\title{
Discrimination against Negroes
}

\author{
By Otis Dudley Duncan
}

ABstRact: The functions of indicators to measure fullness of participation of minorities in American society can best be understood by relating them to strategic junctures in the socioeconomic life cycle. Data for Negroes, in particular, reveal the operation of two types of handicaps - those common to all members of the society subject to disadvantages of background or misfortune, and those specific to minority status. To distinguish between them, and thus to measure progress in reducing discrimination, requires not only comprehensive time series but also methods and models suited to the analysis of causal sequences. Despite the growing fund of valuable indicators of the status of "nonwhite" Americans, a number of statistical hazards must be circumvented before reliable inferences and realistic recommendations become possible. In reaching interpretations in this field, social science should operate as a "third force," complementing the work of policymakers and program-administrators, on the one hand, and civic action groups on the other. Present knowledge is inadequate to the task of formulating specific proposals for redirecting trends. It could rapidly become more nearly adequate with the availability of sufficient resources for research, full cooperation of official statistical agencies, freedom to investigate so-called sensitive problems, and concerted attempts to improve analytical and interpretive models. For the moment, we can only be sure that formidable obstacles remain in the way of achieving freedom from discrimination.

Otis Dudley Duncan, Ph.D., Ann Arbor, Michigan, is Professor of Sociology and Director of the Population Studies Center at the University of Michigan. He serves as a member of the Census Advisory Committee on Population Statistics and of the Panel of Consultants on Social Measurements, Department of Health, Education, and Welfare. He is coauthor, with Beverly Duncan, of The Negro Population of Chicago (1957), coauthor, with Peter M. Blau, of The American Occupational Structure (forthcoming), and author of monographs and articles on human ecology and social stratification. 
$\mathrm{T}$ 1HERE is something to be said for phrasing policy goals (as distinguished from program objectives) in deliberately vague terms. No one can say for sure what is meant by health, welfare, or security, but it is agreed that our affluent society enjoys a greater measure of these desiderata than could have been imagined a century ago; yet it falls short of what we now want. Goals are conditioned by what is known, or at least suspected, to be feasible. Social ideals gain and lose content with the progress of knowledge and the accumulation of experience. Today we recognize as forms of inequality, or manifestations of discrimination, social patterns that were accepted only a few years ago-not because they were then deemed just, but simply because they were still unidentified.

As we bring knowledge to bear upon the achievement of "freedom from discrimination," we shall inevitably alter the very concept of discrimination. Indeed, it may not be premature to forecast a decline in the usefulness of the concept for deliberations on our society's future. Already the operative meaning of this goal is shifting from an emphasis on the mere elimination of various sanctioned and routinized discriminatory practices. What we really want, I suppose, is freedom from the results of discrimination. But since we can only measure -or, actually, infersome of these results, our goal might better be stated in positive but openended terms: freedom of full participation. Remediable limitations on full participation will then appear as undesirable, whether or not one could convincingly attribute them to discrimination in some fairly definite sense of the word. Fullness of participation might come to mean the opportunity to share completely the responsibilities, risks, and hazards of citizenship, as well as the rewards of achievement and acceptance.

\section{FUNCTIONS OF INDICATORS}

In one sense, the measures of welfare and participation needed to ascertain the status and changes of status of a minority presumed to be subject to discrimination are no different from the measures required for the population as a whole-save, of course, that they must be available specifically for the minority as such. We already have much knowledge about the properties and uses of statistical indicators which we are not applying fully to the diagnosis of discrimination or to the measurement of progress (or lack of progress) in removing discrimination. Many of the statistics issued for the total population are also available for the "nonwhite" segment. However, "nonwhites" are not a single minority, but rather a congeries of minorities - Negroes, several distinct groups of Oriental extraction, and Indian-Americans-with very different kinds of social positions and life chances. If the subsequent discussion must rely heavily on contrasts between white and "nonwhite," let it be understood that the latter is merely a more or less unsatisfactory substitute for Negro-American. The possibility of a parallel discussion for other socalled racial categories, not to mention national-cultural or religious minorities, is severely limited by the lack of comparable data.

There is a sense, however, in which the mere availability of parallel series of indicators for the several minority groups (including the "majority," which is simply the largest of the minorities) would not be sufficient to reveal the incidence and effects of discrimination. Limitations on fullness of participation may indeed be suspected from the mere 


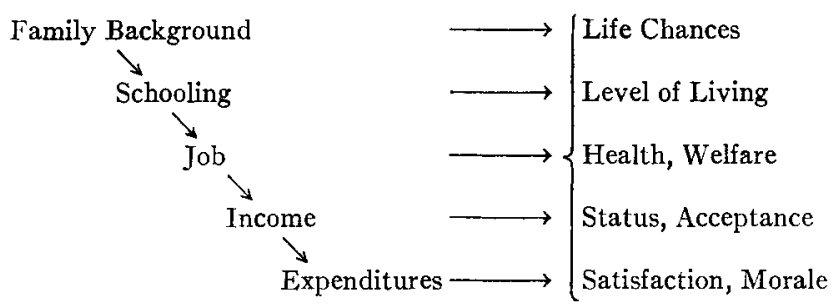

Figure 1-The Socioeconomic Life Cycle: Schematic Representation.

existence of a majority-minority differential, as when it is observed that the median income of families with a nonwhite head was, in 1965,55 per cent of that of families with a white head. What we need to know are the components of this differential: What is the relative importance of lack of equal pay for equal work, the lack of access to equal employment opportunity given equal qualifications, the lack of equal qualifications due to unequal access to training, and so on? Without condoning any of these kinds of inequality, a pragmatic strategy will concentrate first or most heavily on those forms that are most amenable to manipulation by policy and that offer the greatest payoff through a cumulation of direct and indirect effects.

We need, therefore, not only to have comprehensive series of indicators (even though this is the minimum requirement) but also methods, models, and materials suited to disentangle the causal relationships among indicators. The measurement of discrimination itself presupposes analysis of such relationships, for the empirical evidence of discrimination consists, I suppose, in the demonstration of inequality on one measure, after the contributions to that inequality made by variables other than discrimination have been evaluated. Residential segregation, for example, may be taken to measure the extent of discrimination in the housing market only after allowance is made for dif- ferences in ability to pay for housing. ${ }^{1}$ That the latter, in turn, may reflect some other form of discrimination is a separable problem, and the separation had best be made, if we seek understanding and not mere documentation of our lack of progress in achieving full participation.

\section{Two Types of Handicap}

We are already able to suggest a conceptual paradigm, though not yet an operational model, of the "socioeconomic life cycle," which will serve to illustrate the necessity of considering relationships among indicators. The scheme in Figure 1 assumes that in the career of an individual or cohort of individuals the circumstances of the family of orientation-its size, structure, socioeconomic status, stability, and so on-provide a set of "initial conditions" whose effects are transmitted through subsequent stages of attainment and achievement. In focusing on the education - occupation - income-consumption nexus, we are stressing what Moore and Sheldon term the "distributive" variables. ${ }^{2}$ These are surely relevant in many complicated ways to the outcomes

1 Karl E. Taeuber, "Residential Segregation," Scientific American, 213 (August 1965), pp. 12-19.

${ }^{2}$ Wilbert E. Moore and Eleanor Bernert Sheldon, "Monitoring Social Change: A Conceptual and Programmatic Statement," Proceedings of the Social Statistics Section, 1965 (Washington, D.C.: American Statistical Association, 1966), pp. 144-149. 
rather ambiguously designated by terms like "life chances" and "welfare" at the right of the diagram. Other determinants might better be treated in terms of a "sociopolitical life cycle," referring to participation in and actions taken by voluntary and religious organizations, unions, social movements, and political structures and processes proper. Such a complication of our conceptual framework is beyond the scope of a discussion which has already raised issues too complex for more than an overly simplified exposition. As a first, though admittedly unsatisfactory, approximation, the sociopolitical context may be taken as a configuration of "exogenous" influences on the socioeconomic processes to be considered here.

A respectable beginning has been made in uncovering some of the mechanisms of the socioeconomic life cycle, or selected aspects of it, as they operate in the general population of this country. Informative data from longitudinal and retrospective studies on representative samples permit something more than impressionistic estimates of how and how much the advantages or handicaps at one stage are transmitted to the succeeding ones, ${ }^{3}$ Such evidence, however, does not exist for earlier time periods in a form that allows reliable inference of trends. And it does not exist (save in the most rudimentary form for "nonwhites") for the minorities whose life-cycle patterns are presumed to deviate widely from the American norm.

What we can say with some confi-

3 Peter M. Blau and Otis Dudley Duncan, The American Occupational Structure (New York: John Wiley and Sons, in press); Bruce K. Eckland, "Academic Ability, Higher Education, and Occupational Mobility," American Sociological Review, 30 (October 1965), pp. 735-746; William H. Sewell and J. Michael Armer, "Neighborhood Context and College Plans," American Sociological Review, 31 (April 1966), pp. 159-168. dence about the Negro-American in particular is that he is subject to more than his share of the kinds of handicaps that result in lower than average outcomes of the socioeconomic cycle for anyone, white or Negro. Thus, readily available statistics reviewed in accessible sources ${ }^{4}$ indicate that Negroes, in disproportionate numbers, (1) experience unstable family situations and depend on meager family resources; (2) attain less than average amounts of education; (3) are employed in lowerlevel jobs; (4) secure low incomes; (5) have an inefficient pattern of expenditures; and (6) in consequence, are characterized by inferior life chances, low levels of living and welfare, and impaired satisfactions. In the chain of causation which the diagram seeks to suggest, each of these handicaps operates to set up the handicaps at later stages: schooling is terminated early partly because family support is inadequate; job opportunities are inferior partly because educational preparation is not good; low income is partly due to poor job opportunities; expenditures are inefficient and insufficient partly because of low income; Negroes get less out of life partly because of cumulative inadequacies at each stage of the life cycle.

These handicaps, to reiterate, are not peculiar to the incumbents of a particular minority status. They are shared by others whose start in life or subsequent misfortune puts them at

4 Rashi Fein, "An Economic and Social Profile of the Negro American," Dadalus, Proceedings of the American Academy of Arts and Sciences, 94 (Fall 1965), pp. 815-846; U.S, Department of Health, Education, and Welfare, White-Nonwhite Differentials in Health, Education, and Welfare, reprinted from Indicators (February-October, 1965); U.S., Department of Labor, The Negroes in the United States: Their Economic and Social Situation, Bureau of Labor Statistics Bulletin, No. 1511 (Washington, D.C.: U.S. Government Printing Office, 1966). 
a disadvantage. It is only when we superimpose upon these "general handicaps" the collection of "specific handicaps" of racial status that the plight of the Negro begins to be fully revealed: (1) Unstable and inadequate family backgrounds of Negroes are not merely the consequence of "poverty"; they are in part due to segregation. (2) Comparing white and Negro children similar in background, the latter are likely to get less schooling. The same number of years of schooling means less education for the Negro, owing to separate and unequal education. (3) With the same educational preparation, job discrimination by employers and unions handicaps the Negro in the labor market. (4) For the same work-or, at any rate, at the same occupational level-the Negro gets less pay and less job security. (5) At the same income level, limitations on credit and lack of access to some parts of the market render the Negro's dollar less effective in buying power. (6) At the same positions on scales of educational and occupational achievement and at similar levels of living and welfare, the Negro's social status suffers in the estimate of the general population-even when he "has it made" he has not.

Although these conclusions can be stated with some confidence, we actually do not yet have many adequate analyses of the respective roles of general handicaps and minority-specific handicaps in quantitative terms. There are only a few painstaking studies which come to grips with the problem of estimating the "cost of being Negro"; 5 and, to repeat, such estimates are, by and large, not yet possible for minorities other than Negroes or for different periods of time. The issue is not one of academic nicety, for any program de-

\footnotetext{
${ }^{5}$ Paul M. Siegel, "On the Cost of Being a Negro," Sociological Inquiry, 35 (Winter 1965), pp. 41-57.
}

signed to move the society toward fullness of participation will be built on assumptions as to the relative proportions of general and specific handicaps and their relative responsiveness to various methods of inducing change.

\section{Statistical Resources}

An evaluation of gaps in our information can proceed either from a comparison between what we do know and what we should know, or from an identification of discrepancies between what we do know and what we could know, assuming merely a concerted application of presently available techniques. The latter, more modest, criterion is accepted here, since the goals of social measurement, like the goals of society itself, expand as our capabilities are augmented. ${ }^{6}$

B This section and subsequent discussion are based on a comprehensive review of existing and potential time series of social statistics that shed light on the status of the Negro population: Otis Dudley Duncan, "Social Mobility of the American Negro: Prospects for a Program of Studies," unpublished discussion paper drafted for the Public Affairs Program of the Ford Foundation, 4 June 1964. The memorandum included an "Inventory of Data Needs and Resources" in each of the following categories: school attendance and educational attainment; employment, occupation, industry, and union membership; income, possessions, health, consumer expenditures, and welfare and social security; housing; family composition and illegitimacy; political participation; crime, delinquency, and the administration of justice; social acceptance, morale, aspiration, and cultural assimilation; basic demography. The inventory is partially updated by the items listed in footnotes $4,14,22,24$, and 26 , and by recent publications of the United States Bureau of the Census, 1960 Census of Population, Supplementary Reports, PC (S1)-46, "Subject Guide to 1960 Census Data for the Negro Population" (April 7, 1964); Current Population Reports, Series P-20, No. 142, "Negro Population: March 1964" (October 11, 1965); ibid., No. 155, "Negro Population: March 1965" (September 27, 1966). See also the discussion of "statistics of opportunity" in Otis Dudley 
Information, of a sort, on the condition of one minority was built into the very foundations of our statistical system with the provision of the Constitution (Article I, Section 2) for apportionment of representation among the States "according to their respective numbers, which shall be determined by adding to the whole number of free persons, including those bound to service for a term of years, and excluding Indians not taxed, three-fifths of all other persons." In addition to the count of "all other persons," the First Census provided a classification of the free population by color.

Statistics by race or color have been collected at every subsequent census, though it is curious to note the apparent changes in the purpose and associated practices of this statistical work. In his report of May 1862 to the Senate, the Superintendent of the 1860 Census described the "progress and decline of African slavery in our country." Taking note of the higher rate of increase of the slave than of the free colored population, he ventured to forecast that "if large numbers of slaves shall be hereafter emancipated, so many will be transferred from a faster to a slower rate of increase."

A concern with race mixture presumably occasioned in 1850 the introduction of the subcategory, "mulatto," which continued in use through 1910 despite the admitted uncertainty of the classification. Popular anthropology was given free rein in the Census of 1890 , where the term "black" refers to persons "having three-fourths or more black blood," other persons with any proportion of "black blood" being classified as "mulattoes," "quadroons," or "octoroons."

Duncan, "The 1970 Census: Challenge and Opportunity," 1966 Proceedings of the Social Statistics Section (Washington, D.C.: American Statistical Association, 1966), pp. 2-6.
The monumental report of the Census Bureau, Negro Population, 1790-1915, issued in 1918, undertook to document the "progress of the Negro race." Symptomatic of that progress, one is led to suppose, was the circumstance that "the tabulations for this report were made by a corps of Negro clerks working under the efficient direction of three men of their own race." Its successor of 1935, Negroes in the United States, 1920-1932, likewise was based on the work of "a corps of Negro clerks." The scope of these two reports has not been matched in any more recent official compilations. The 1935 report, for example, includes sections on Negro religious bodies and retail establishments, as well as occupations and strictly demographic topics.

While the Censuses of 1940, 1950, and 1960 include voluminous tabulations for white and "nonwhite" persons, the recording of the "progress of the Negro race" is no longer a featured subject of textual discussion. The recently revived attention to statistics on Negroes (rather than "nonwhites") evidently is a response, rather, to the current interest in civil rights and racial equality. For some time, the Bureau of the Census has been careful to emphasize that "the concept of race... is derived from that which is commonly accepted by the general public. It does not, therefore, reflect clear-cut definitions of biological stock."

Table 1 assembles data illustrative of the kinds of annual time series that are available in regular statistical reports. While vital statistics and some kinds of administrative information (like the series on executions) are available for several decades, much of our present capability rests upon the expansion of the work of the Bureau of the Census into the area of monthly and annual sample surveys, following World War II. The illustrations are not meant to 
Table 1-Illustrative Time Series of Annual Data (Averages for Three-Year Periods) for the Nonwhite (N) and White (W) Population of the United States: 1948-1965

\begin{tabular}{|c|c|c|c|c|c|c|c|}
\hline \multirow{2}{*}{\multicolumn{2}{|c|}{ SERIIS }} & \multicolumn{6}{|c|}{ PERIOd } \\
\hline & & \multirow{2}{*}{$\frac{1948-50}{70.7}$} & \multirow{2}{*}{$\begin{array}{r}1951-53 \\
75.5\end{array}$} & \multirow{2}{*}{$\frac{1954-56}{83.1}$} & \multirow{2}{*}{$\frac{1957-59}{86.2}$} & \multirow{2}{*}{$\frac{1960-62}{88.8}$} & \multirow{2}{*}{$\frac{1963-65}{92.4^{*}}$} \\
\hline School Enrollment, Per Cent of Males & $\mathrm{N}$ & & & & & & \\
\hline Age $14-17$ & W & 84.5 & 87.2 & 89.6 & 91.7 & 92.9 & $94.6^{\mathrm{a}}$ \\
\hline \multirow{2}{*}{$\begin{array}{l}\text { Per Cent High School Graduates, } \\
\text { Male Labor Force }\end{array}$} & $\mathrm{N}$ & $(\mathrm{NA})^{\mathrm{e}}$ & $15.1^{\mathrm{b}}$ & (NA) & $21.7^{\mathrm{b}}$ & $27.3^{\mathrm{b}}$ & $32.3^{\mathrm{a}}$ \\
\hline & W & (NA) & $42.1^{b}$ & (NA) & $49.4^{\mathrm{b}}$ & $53.5^{\mathrm{b}}$ & 56.8 \\
\hline \multirow{2}{*}{$\begin{array}{l}\text { Per Cent of Male Workers with Year- } \\
\text { round Full-Time Jobs }\end{array}$} & $\mathrm{N}$ & $50.2^{\mathrm{b}}$ & 53.0 & $55.6^{\mathrm{s}}$ & 51.3 & 51.8 & $55.2^{\mathrm{a}}$ \\
\hline & W & $66.8^{b}$ & 69.9 & $68.8^{\mathrm{a}}$ & 66.0 & 65.3 & $67.2^{\mathrm{a}}$ \\
\hline \multirow{4}{*}{$\begin{array}{l}\text { Per Cent of Employed Persons in } \\
\text { White-collar Jobs } \\
\text { Median Income of Families (Dollars) }\end{array}$} & $\mathrm{N}$ & $9.6^{\mathrm{a}}-\mathrm{c}-\mathrm{c}-\mathrm{c}$ & $9.7 \mathrm{~b}$ & $12.2^{\mathrm{a}}$ & $14.0^{\mathrm{a}}$ & 16.4 & 18.6 \\
\hline & W & $39.7^{\mathrm{a}}$ & $39.8^{\mathrm{b}}$ & $42.2 \mathrm{a}$ & $45.6^{\mathrm{a}}$ & 46.8 & 47.2 \\
\hline & $\mathrm{N}$ & 1,762 & 2,277 & 2,529 & 2,797 & 3,251 & 3,758 \\
\hline & W & 3,329 & 4,122 & 4,646 & 5,370 & 6,018 & 6,859 \\
\hline \multirow[t]{2}{*}{ Infant Deaths per 1,000 Live Births } & $\mathrm{N}$ & 46.1 & 45.5 & 42,6 & 44.4 & 41.8 & $41.3^{\mathrm{s}}$ \\
\hline & W & & 25.4 & 23.6 & 23.4 & 22.5 & $21.9^{\mathrm{a}}$ \\
\hline \multirow{2}{*}{$\begin{array}{l}\text { Deaths from Tuberculosis per } 100,000 \\
\text { Population }\end{array}$} & $\mathrm{N}$ & 71.5 & 42.2 & 21.9 & 16.2 & 12.3 & $10.4^{\mathrm{a}}$ \\
\hline & W & 21 & 1 & 7.7 & 6.0 & 4.6 & $3.8^{\mathrm{a}}$ \\
\hline \multirow[t]{2}{*}{ Homicides per 100,000 Population } & $\mathrm{N}$ & 29.1 & 26.1 & 23.6 & 22.0 & 21.5 & $22.4^{\mathrm{s}}$ \\
\hline & W & 2.8 & 2.5 & 2.3 & 2.4 & 2.6 & 2. \\
\hline \multirow{2}{*}{ Suicides per 100,000 Population } & $\mathrm{N}$ & 4.2 & 3.9 & 3.9 & 4.3 & 4.6 & 4.8 \\
\hline & W & 12.2 & 10.9 & 10.9 & 11.1 & 11.4 & $11.8^{\mathrm{a}}$ \\
\hline \multirow{2}{*}{$\begin{array}{l}\text { Per Cent of Married Women with } \\
\text { Husband Absent }\end{array}$} & $\mathrm{N}$ & (NA) & 16.0 & 19.6 & 20.3 & 19.8 & 21.0 \\
\hline & W & (NA) & $4.6^{\mathrm{a}}$ & 5.0 & 4.2 & 4.3 & 4.4 \\
\hline \multirow[t]{2}{*}{ Subfamilies per 100 Families } & $\mathrm{N}$ & 12.1 & $10.1^{\mathrm{a}}$ & 10.4 & 9.2 & 7.4 & 6.4 \\
\hline & W & 6.1 & $4.4^{\mathrm{a}}$ & 4.2 & 3.4 & 2.8 & 2.4 \\
\hline \multirow[t]{2}{*}{ Births per 1,000 Women Age $15-44$} & $\mathrm{~N}$ & 135 & 144 & 156 & 162 & 152 & $143^{\mathrm{s}}$ \\
\hline & W & 103 & 110 & 114 & 116 & 111 & $102^{\mathrm{a}}$ \\
\hline \multirow[t]{2}{*}{ Per Cent of Live Births Illegitimate } & $\mathrm{N}$ & 17.1 & 18.6 & 20.2 & 21.2 & 22.3 & $24.0^{\mathrm{a}}$ \\
\hline & W & 1.8 & 1.6 & 1.9 & 2.1 & 2.5 & 3. \\
\hline \multirow{2}{*}{$\begin{array}{l}\text { Per Cent of Aged Population Re- } \\
\text { ceiving OASDI Benefits }\end{array}$} & $N$ & 9.3 & 18.3 & 28.4 & 41.0 & 53.0 & 65.0 \\
\hline & W & 17.3 & 30.0 & 43.8 & 59.4 & 69.6 & 77.0 \\
\hline Prisoners Executed under Civil & $\mathrm{N}$ & 65 & 42 & 40 & 31 & 25 & 5 \\
\hline Authority, Annual Number & $\mathrm{W}$ & 42 & 41 & 34 & 23 & 23 & 9 \\
\hline
\end{tabular}

B Based on data for only two years.

${ }^{b}$ Data for only one year.

- NA: Not available.

Source: Varìous federal publications; Old-Age and Survivors Disability Insurance Program (OASDI) figures from unpublished calculations of the Office of Research and Statistics, Social Security Administration.

represent the full scope of the current statistical series, and do not include at all the many valuable items of information that become available decennially or on a one-time basis. They do, however, provide instructive samples of the tasks that would challenge an enterprise devoted to assembling the raw information for productive deliberations on means and ends in the struggle for full participation. In fact, several of the series are shown because they exemplify some of the more serious difficulties of analysis and interpretation, and, thus, the kinds of qualifications that would have to accompany their inclusion in an official or unofficial Social Report on Freedom from Discrimination.

\section{Statistical Hazards}

The first obstacle-let us face it honestly -is that figures usually do not mean what they appear to mean. This is not to endorse the popular estimate 
that places statistics in a category of veracity somewhat lower than "damned lies." Rather, it is to emphasize that no isolated item of information, quantitative or verbal, is self-explanatory. It can only take on a reliable meaning or guide an intelligent decision when placed in a context. Statisticians, contrary to popular assumption, are not fond of quoting single figures as measures of progress or predicament-that is a fine art most assiduously cultivated by nonstatisticians in election years.

Among the elementary cautions in interpreting time series, like the examples in Table 1, are these: (1) Large relative gains come easier from a starting point near the floor than from one approaching a ceiling. Thus, white-collar employment for nonwhites doubled during the one and one-half decades covered by Table 1 , and could easily double again in a subsequent period of equal length, but school enrollment at ages fourteen to seventeen could increase by no more than 50 per cent after 1949 , having already reached seven-tenths of its ceiling value by then. (2) Absolute differences often give an opposite impression from that conveyed by relative differences. At the beginning of the period covered in the table, the nonwhite illegitimacy ratio was 9.5 times as large as the white; at the end, 7.5 times. In terms of the nonwhitewhite difference in percentages, however, the change was from 15.3 to 20.8 . (3) The quantities in a time series often require one or more kinds of rudimentary standardization before any interpretation can be ventured. Comparisons of tuberculosis death rates should take into account differences in age composition. Changes in dollar income should be measured against changes in the value of the dollar. Figures on executions must be related to the number exposed to risk - the respective population sizes or, better, numbers convicted of capital offenses. Where the statistical agency or analyst does not provide such adjustments, the sophisticated reader should at least make rough mental allowances for their probable effect. Thus, it is clear that Negroes have been disproportionately subject to capital punishment, given the recent approximate equality of the absolute numbers of executions of whites and nonwhites as against the fact that nonwhites are about one-ninth of the population.

Other hazards may be less evident, but nonetheless real. The illegitimacy ratio is based in part on estimates, and the estimating technique and probable range of error have not been adequately evaluated. After 1959, the birth series are no longer "corrected for underregistration." This introduces a discontinuity into the series and raises some question about the validity of the corrections for earlier years. Figures on school attendance may give rise to misleading impressions if no allowance is made for differences in age-grade relationships. The entry of "suicide" as the cause of death on the death certificate is often a matter of judgment or conjecture on the part of the physician, and no one knows (for example) how many automobile accident fatalities, recorded in another category of violent deaths, occurred to drivers in a suicidal frame of mind. A number of the series in Table 1 are based on samples, and the figures for nonwhites are subject to relatively high sampling errors, even after taking three-year averages.

If the foregoing kinds of qualifications may be regarded as "technical" difficulties in the interpretation of time series, there are still more difficult issues that arise even in the case of series whose statistical properties are wholly satisfactory. These pertain to the causal interrelations and the social "meaning" of the changes. 
One writer has argued that we should eschew comparisons of rates of change, as well as measures of change in either absolute or relative differences. He proposes instead of these conventional indicators of convergence or divergence a "time-lag statistic: how many years earlier did the white American .... attain the particular level (say, of health, education, income) that the Negro ... . has reached only today." 7 Changes in the length of this period, which we may wish to term the "Fein gap," after its inventor, are taken to be indicative of whether the Negro is catching up or falling behind. These will often tell a different story than will the other measures of discrepancy. Indeed, if there is anything to the theory of the "privilege of backwardness," the mere failure of the Fein gap to diminish over the years, even though both white and Negro indicators are in the direction of improvement, suggests a degree of exclusion from the fruits of social progress.

Obviously, there are both technical and conceptual limitations on the analysis of Fein gaps. For one thing, many series are not long enough or frequent enough for them to be ascertained reliably. The very concept is applicable, moreover, only to series that have a cumulative, evolutionary, or progressive character. They are well suited, in theory, to measures of health, education, and income, but less so to indicators of family structure and function, for example, although the latter are suspected to have strong bearing on opportunities and participation.

Even where calculation of the Fein gap lends meaning to data on "the progress of the Negro race," we only have a better description of the predicament, but not an explanation of it, not to mention a directive for appropriate meliorative action. Large values of this statistic or unfavorable changes in it

\footnotetext{
7 Fein, op. cit., pp. 817-819.
}

may signalize a social problem, but do little to pinpoint its causes or to suggest its remedies.

This is an important distinction. Hence, I should like to emphasize it with a figure of speech, at the risk of introducing misleading connotations.

A particular series may be either "symptomatic" or "diagnostic," or sometimes both. The treatment it may seem to call for can be directed toward symptoms or causes, or both. Interpretation and action, if they are not to be misconceived or misdirected, presuppose analysis. For illustration, the series on percentage of aged persons receiving OASDI benefits (Table 1) serves, symptomatically, to sum up aspects of the history of labor-force participation and employment of the cohorts qualifying for benefits on the basis of age:

In the early days of the social security program, the exclusion of farm labor, domestic service, and certain other types of work from the system meant that relatively fewer Negroes than white persons could share in the protection offered. . . The 1950, 1954, and 1956 amendments removed most of the restrictions from coverage. These liberalizations, as well as the accelerated movement of the Negro from farm work into city jobs, mean that more and more Negroes have a stake in the oldage, survivors, and disability insurance program. ${ }^{8}$

The quotation suggests the lines of analysis that would have to be explored to explain the color differential, its yearby-year changes, and the fact that the Fein gap for this series has varied between about 3 and 4.5 years over the period 1946-1965. The series is a composite result of heterogeneous causes, the disentangling of which invites a substantial research effort.

Such an effort is indeed required if

${ }^{8}$ Mollie Orshansky, "The Aged Negro and His Income," Social Security Bulletin, 27 (February 1964), p. 9. 
we should try to devise a program to shorten the Fein gap or if we should seek to estimate whether existing programs or those contemplated for other reasons will have this effect. The series as it stands has little "diagnostic" value, but is of considerable "symptomatic" interest.

To be sure, programs to treat symptoms are no more to be disdained than is the analogous procedure in medical practice, provided the practitioner is clear about what he is doing. The symptomatic data suggest that current income-maintenance programs for the immediate future will require provisions to compensate for the differential coverage of OASDI, even as we work to contrive manpower policies and social insurance schemes that ultimately will remove the causes of the discrepancy.

Other examples of primarily "symptomatic" series will be found in Table 1 . When the Fein gap in suicide rates has been reduced to zero, we will know that the Negro-American has attained his full share of the kinds of troubles afflicting other Americans, and "freedom from discrimination" will probably be a dead issue.

\section{INTERPRETATIONS AND MODELS}

My argument implies that no elaboration or refinement of the function of "social bookkeeping"-essential as improvements therein surely are-will ultimately satisfy the need for statistical intelligence as a basis for policyformulation and program-evaluation. Policies and programs involve a meansends calculus predicated upon dependable knowledge of cause-and-effect relationships. We are familiar with this pattern of connections between knowledge and action in the strictly economic sphere, as when monetary, fiscal, and tax measures are calculated in the light of theories and measurements predicting their effects on employment and prices. It hardly needs to be argued that present theory and measurement practices are not adequate for such calculation in the realm of social opportunities. Even if we had a "Council of Social Advisors" to complement the work of the Council of Economic Advisors, it is not wholly clear what their charge should be.

Yet the present state of the art would permit much more to be done with a modest expansion of our allocation of resources to the problem. We have empirical relationships between education, employment, occupational status, family structure, and income, for example, or can readily develop same from statistics on hand or in the files of datacollection agencies. Analysis of past changes or projections of future changes should be able to suggest how much of the gap in income is due to the gap in education, how much to less-than-full employment, and how much to inequality of compensation at equivalent occupational levels and for equivalent periods of work. Well-known and rudimentary statistical techniques of cross-tabulation, covariance and regression analysis, direct and indirect standardization, and the like can be brought into play so that the statistical information implicit in our present datacollection systems is made to yield something closer to a realistic "estimate of the situation" than can be had from a mere congeries of "facts."

Sometimes even a simple rearrangement of data lying at hand will yield unexpected insights. One gets a rather different perspective on comparative occupation trends, for example, when the data are arranged so as to highlight changes over time for identical cohorts, defined by year of birth and subdivided by amount of formal education. Reversal of the previous trend of whitenonwhite convergence in occupation distributions of young college graduates 
during the 1950's, for example, suggests a restoration of some of the barriers that had been temporarily breached during and immediately after World War II. ${ }^{\circ}$

The tendency of these remarks, therefore, is to register dissatisfaction with any plan that stops with periodic compilation and display of "indicators" of the extent or degree of discrimination, and still more dissatisfaction with any proposal to produce a single "index" of the status of a minority group.

The National Commission on Technology, Automation, and Economic Progress, in its recently issued report, ${ }^{10}$ has seized upon a remark of Myrdal: "We should ... . have liked to present in our study a general index, year by year or at least decade by decade, as a quantitative expression of the movement of the entire system we are studying: the status of the Negro in America." 11 Neither the Commission nor others who have been intrigued by the notion of a "general index" studied closely enough Myrdal's further remarks, in which he virtually retracted his advice to engage in the construction of "a general index of Negro status" in favor of a more penetrating prescription: "Ideally, the scientific solution of the Negro problem should . . . be given in the form of an interconnected series of quantitative equations, describing the movement of the actual system under various influences. ... [T] his complete, quantitative and truly scientific solu-

${ }^{9}$ Nathan Hare, "Recent Trends in the Occupational Mobility of Negroes, 1930-1960: An Intracohort Analysis," Social Forces, 44 (December 1965), pp. 166-173. See also Dorothy S. Brady, Age and the Income Distribution, Social Security Administration $\mathrm{Re}-$ search Report No. 8 (Washington, D.C.: U.S. Government Printing Office, 1965).

${ }^{10}$ Technology and the American Economy, Vol. 1 (Washington, D.C.: U.S. Government Printing Office, 1966), p. 98.

11 Gunnar Myrdal, An American Dilemma (New York: Harper, 1944), p. 1068. tion ... remains as the scientific ideal steering our endeavors." ${ }^{12}$ The Commission may have improved upon this formulation-though I doubt it-in asking for "a system of social accounts," the specifications for which are barely adumbrated in the Commission's report.

\section{Social Science: A Third Force}

It gives one pause, moreover, to encounter the Commission's recommendation that the task of developing a "system of social accounts" be taken over by the Council of Economic Advisers. The Commission correctly assumed that most of the sources for this enterprise would consist of time series organized for continuous and regular production by federal statistical agencies. Casual acquaintance with the capabilities of these agencies does, indeed, suggest that they are ill-suited to assume responsibility for an "accounting system." It does not follow that the only alternative is to assign it to an official policy-making body. Although the interaction of policy-formulation and policy-defense with scientific analysis is still inadequately understood, I believe careful scrutiny of social research conducted intramurally (within the federal establishment) will reveal too many instances where the two functions have been confounded to an undesirable degree. An "official theory" to the effect that school dropout is a major source of various social pathologies is too easily converted into statistical procedures which virtually preclude an independent assessment of the merits of this theory and of its cogency as an intellectual cornerstone of current programs. ${ }^{13}$ (The reader may be familiar with other examples, such as those stemming from official and

12 Ibid, p. 1069.

13 Beverly Duncan, "Early Work Experience of Graduates and Dropouts," Demography (in press). 
unexamined assumptions about the "inheritance of poverty.")

I would propose as an alternative at least worth discussion that the continuing task of assessing movement toward freedom from discrimination be accepted by a privately organized enterprise which might, to be sure, come to enjoy a paragovernmental status in view of its inescapable reliance on federal statistical resources and its requirement for continuous liaison with the relevant agencies. It would be mandatory, however, for such a unit to be independent of the administrative apparatus and of any commitment to the specific programs of the party currently in office. It would require substantial resources to undertake continuing inquiries on matters too "sensitive" for direct federal surveillance ${ }^{14}$ and to command the continuing participation of some of the best minds in the social sciences. Among other things, such a body would be free to criticize the actions of government (and especially the assumptions underlying them) and to assess in a nonpartisan mood the government's progress as well as that of civil society in moving toward fullness of participation.

Perhaps this is what the aforementioned National Commission had in mind in suggesting that "some national body of distinguished private citizens . . . be concerned with 'monitoring' social change, forecasting possible social trends, and suggesting policy alternatives to deal with them." 15 That a minority of the Commission itself took

${ }^{14}$ For example, the studies undertaken by the National Opinion Research Center and by Louis Harris and Associates; see Paul B. Sheatsley, "White Attitudes toward the Negro," Dadalus, Proceedings of the American Academy of Arts and Sciences, 95 (Winter 1966), pp. 217-238; William Brink and Louis Harris, The Negro Revolution in America (New York: Simon and Schuster, 1964).

${ }^{15}$ Technology and the American Economy, op. cit., p. 106. exception to this recommendation may suggest that the initiative needs to be taken in the private sector.

\section{Targets and Trends}

Developments of the last decade reflect the recrudescence of an interest in measuring social trends which had been dormant since the early 1930's. Perhaps it was the preoccupation with the exigencies of the Depression that precluded an adequate follow-up to the beginning made with Recent Social Trends ${ }^{16}$ and the short-lived annual series on social changes issued by the American Journal of Sociology. ${ }^{17}$ The revival was presaged by the monumental efforts devoted to Historical Statistics and the continuations and revisions thereof. ${ }^{18}$ Within the last decade we have seen much activity in compiling, presenting, and discussing "trends" and "indicators," both on the part of government agencies and in academic circles. ${ }^{19}$

Perhaps this is the time-while applauding and encouraging such activity - to undertake a re-examination and appraisal of the philosophy and methods of trend-analysis. Karl Popper has given us a start on the former with his profound aphorism: Trends are not

16 President's Research Committee on Social Trends, Recent Social Trends in the United States (New York: McGraw-Hill, 1933).

17 Vols. 34-40, 47 (1929-1935, 1942), edited by William F. Ogburn.

18 U.S., Bureau of the Census, Historical Statistics of the United States, 1789-1945 (Washington, D.C.: U.S. Government Printing Office, 1949); Historical Statistics of the United States: Colonial Times to 1957 (Washington, D.C.: U.S. Government Printing Office, 1960); Historical Statistics of the United States: Colonial Times to 1957: Continuation to 1962 and Revisions (Washington, D.C.: U.S. Government Printing Office, 1965).

${ }^{19}$ U.S., Department of Health, Education, and Welfare, $H E W$ Trends (annual) and $H E W$ Indicators (monthly); Raymond A. Bauer (ed.), Social Indicators (Cambridge, Mass.: M.I.T. Press, 1966). 
laws. ${ }^{20}$ The movements of a time series do not represent a trajectory whose history reveals its own law of motion so that the terminus ad quem is in principle predictable from the record of the past. We might well abandon the ballistic imagery, including reference to targets, if it is going to betray us into the expectation that trend-analysis will by itself provide a means of knowing what is going to occur and how soon.

Trends are merely the raw material of social analysis, and improvements in their measurement only accentuate the challenge to grapple with fundamental issues of social causation. As a purely empirical proposition, it may well be, as Ogburn claimed, ${ }^{21}$ that extrapolating a trend is likely to yield a smaller forecasting error than assuming that next year will be the same as last year. Yet this rule provides no basis for anticipating reversals or changes in trends and little basis enough even for understanding past alterations of their directions.

Of course, we now take "target" to refer, not to the level that a trend will seek out of its own accord, but to the magnitude that we hope we can cause it to attain. Save, perhaps, for some restricted areas of the economic realm, procedures for specifying targets in this sense are far too primitive to be dignified by referring to them as "methods." Even where we have contrived massive social experiments in response to major problems, the opportunity has seldom been seized to analyze them by techniques simulating (as closely as can be) those suited to making inferences from experiments. Two decades after the fact, who can say on any scientific

20 Karl R. Popper, The Poverty of Historicism (Boston: Beacon Press, 1957), pp. $115 \mathrm{ff}$ 21 "Social Trends," in William F. Ogburn on Culture and Social Change, ed. by $\mathrm{O}$. D. Duncan (Chicago: University of Chicago Press, 1964). basis what the social effects of the "G.I. Bill of Rights" have been? If we cannot assess the efficacy of past expedients, dare we project the impact of current ones?

Lacking method, we hope for wisdom-a small hope, perhaps, but not a negligible one. A beginning of wisdom can be found in a simply stated principle: some things are easier to change than others (a thinly disguised paraphrase of the hypothesis of cultural lag).

The principle explains, among other things, why it is possible to find all kinds of evidence of "progress" in the time series portraying the status of the Negro minority, but at the same time to "prove"-resorting to figures in lieu of "damned lies"-that we are standing still or falling behind in removing discrimination. Not all forms and consequences of discrimination will disappear all at once, ${ }^{22}$ and this is why the "general index" of Negro status will remain a statistical fantasy.

Let me summarize some net impressions, not as scientific conclusions but as propositions whose disconfirmation would put us ahead of where we are now in understanding our predicament.

(1) There are two areas of bedrock resistance to "the progress of the Negro race": residential segregation and the weakness of Negro family structure. The appraisal of the former is, broadly speaking, hardly controversial. We are making scarcely any gain in reducing apartheid in housing. ${ }^{23}$ Yet even the

22 G. Franklin Edwards, "Community and Class Realities: The Ordeal of Change," Dodalus, 95 (Winter 1966), pp. 1-2.3.

23 The definitive work which conveys this distressing intelligence (Karl E. Taeuber and Alma F. Taeuber, Negroes in Cities [Chicago: Aldine, 1965]) provides a base line for the needed program of measuring segregation patterns at least quinquennially. Unfortunately, the rate of change of the segregation index used by the Taeubers is so slow, owing to 
militant edge of the civil rights movement has come to define this as a strategic focus only in recent months. Social analysts have been preoccupied up to now with the arduous task of measuring the trend, or lack of trend, in segregation indexes. They will next turn, we may hope, to the even more difficult problem of testing our suspicions concerning its profound importance as an obstacle to change in contexts not manifestly linked to housing patterns.

The diagnosis of the situation in Negro family life, by contrast, is controversial indeed (as witness the reception of the "Moynihan Report"). Yet there cannot be much argument with the facts: the illegitimacy ratio does not go down; the prevalence of rearing in broken families does not decrease; the proportion of families headed by females does not decline; the undoubling of households, represented by reduction in the ratio of subfamilies to families (Table 1), probably reflects improved economic conditions and some increase in the supply of housing, but may actually indicate a loosening of the bonds of the extended family. Whatever the inadequacies of the educational system, we now know that the school is presented at the beginning of the first grade with children whose family experience has not prepared them intellectually for competition with the majority. ${ }^{24}$

(2) The record on strictly socioeconomic measures can only be described as mixed. Averages of educational attainment, occupational status, and income disclose a rising trend for nonwhites as for whites. One can discount

the inertia of segregation patterns, that more frequent measurement would be merely redundant. For this purpose among others, however, a mid-decade census is badly needed. 24 U.S., Office of Education, Equality of Educational Opportunity (Washington, D.C.: U.S. Government Printing Office, 1966), especially pp. 221-222. or exaggerate the trends by manipulating ratios, absolute differences, and Fein gaps. Closer study of the underlying statistical distributions only compounds the confusion. In the movement toward near-universal literacy, the white and nonwhite series converge; analyzing the proportions continuing from high school graduation on to college graduation reveals a widening of the gap. The obstacle to our understanding here, as I have tried to suggest already, is not a lack of "indicators," but a failure to conceptualize adequately the interrelations of contingencies in the socioeconomic life cycle and to produce quantitative estimates of the relative importance of various sources of change.

(3) Measures of life chances and welfare again offer the opportunity to discern contradictory tendencies. The trends suggest that we are applying (if too slowly) our knowledge of how to reduce death rates from infectious disease and the proportions of living in housing classified as "substandard" by current administrative definitions. While reasons can always be found to be dissatisfied with rates of progress, we could even risk some projections of trajectories to their "targets" in some of the magnitudes subsumed under these categories. To focus attention on them unduly would be to engage in self-congratulation while avoiding the more treacherous areas of analysis and decision.

\section{INTERRELATIONSHIPS}

Here, as in earlier parts of the discussion, I must emphasize the basic obstacle impeding a responsible attempt to designate "targets": It is not a lack of sufficient "indicators" (though we could do with many more regular and reliable time series), but a lack of knowledge of causal connections among indicator variables. To illustrate how 
grave this weakness really is, let me summarize the best example I have been able to find dealing with time changes in an indicator in relation to antecedent variables in the socioeconomic life cycle. It hardly amounts to the "interconnected series of quantitative equations" that Myrdal called for, but it does suggest that our present analytical capabilities have outrun the supply of data suited to multiple-variable analysis.

The example pertains to educational attainment, indexed by number of years of formal schooling completed. We are well aware of the importance popularly and officially attributed to raising the level of schooling in the Negro population. ${ }^{25}$ Family background has been implicated in the "tangle of pathology" that holds back Negro educational achievement: "The effect of broken families on the performance of Negro youth has not been extensively measured, but studies that have been made show an unmistakable influence." 26

The regression statistics summarized in Table 2 pertain to a causal model in which educational attainment of whites and nonwhites depends on four familybackground characteristics: the educational attainment of the head of the family in which the individual grew up; the occupational level of the family head; the classification of the family as intact (grew up with both parents) or broken (grew up in a family with one or both parents missing); and the number of children in the family (respondent's number of siblings). The data permit white-nonwhite comparisons of the estimated effects of these influences on schooling for three age groups: $47-61,37-46$, and 27-36. The age

25 Wilbur J. Cohen, "Social Policy for the Nineteen Seventies," Health, Education, and Welfare Indicators (May 1966).

26 U.S., Department of Labor, The Negro Family: The Case for National Action (Washington, D.C.: U.S. Government Printing Office, 1965), p. 36 . progression in data ascertained retrospectively in 1962 for all three groups provides a tolerable approximation to time-series observations on successive cohorts completing their educational careers. $^{27}$

In several respects, there is a rather stable pattern of relationships evident in these data spanning approximately onethird of a century of educational experience. For all three cohorts of both whites and nonwhites, it was an advantage to grow up in an intact family whose head had achieved high levels of schooling and occupational status, and a disadvantage to grow up with a large number of siblings. There is a fairly clear indication, as well, of the relative importance of the four variables that here represent "family background" (see especially the lower panel of Table 2). Education and occupation of family head account for larger parts of the variation in schooling than do intact family and number of siblings. For whites, head's occupation has been slightly more important than head's education, while the reverse has held for nonwhites. Apart from the rather anomalous coefficient for number of siblings in the youngest group of nonwhites, size of family of orientation has been a more important factor than rearing in an intact family.

Because of the rather high sampling variability in the data for nonwhites, caution must be exercised in inferring time changes in the relationship of schooling to background factors. It may be significant, however, that the effect of intact family diminished for

27 Beverly Duncan, Family Factors and School Dropout: 1920-1960, Co-operative Research Project No. 2258, United States Office of Education (Ann Arbor: University of Michigan, 1965). This source provides a more elaborate analysis for more detailed age intervals. See also Beverly Duncan, "Education and Social Background," American Journal of Sociology, 72 (January 1967), pp. 363-372. 
TABLE 2-Regression of Number of Schoot Years Completed on Family-Background Variables, by Color, for Selected Age Groups of U.S. Native Males: March 1962

\begin{tabular}{|c|c|c|c|c|c|c|}
\hline \multirow{2}{*}{$\begin{array}{l}\text { COLOR AND } \\
\text { AGE IN } 1962\end{array}$} & \multicolumn{5}{|c|}{ INDEPENDENT VARIABLES } & \multirow{2}{*}{$\begin{array}{l}\text { Coefficient of } \\
\text { Determination }\end{array}$} \\
\hline & Color & $\begin{array}{l}\text { Education of } \\
\text { Family Head }\end{array}$ & $\begin{array}{l}\text { Occupation of } \\
\text { Family Head }\end{array}$ & Intact Family & $\begin{array}{l}\text { Number of } \\
\text { Siblings }\end{array}$ & \\
\hline & \multicolumn{6}{|c|}{ Partial Regression Coefficients, Raw Form } \\
\hline \multicolumn{7}{|l|}{ Total } \\
\hline 27 to 36 & 0.843 & 0.197 & 0.040 & 0.744 & -0.199 & .277 \\
\hline 37 to 46 & 1.956 & 0.196 & 0.042 & 0.659 & -0.222 & .312 \\
\hline 47 to 61 & 2.061 & 0.229 & 0,047 & 1.116 & -0.213 & .325 \\
\hline \multicolumn{7}{|l|}{ White } \\
\hline 27 to 36 & $\cdots$ & 0.192 & 0.040 & 0.671 & -0.225 & .267 \\
\hline 37 to 46 & $\ldots$ & 0.195 & 0.041 & 0.626 & -0.223 & .281 \\
\hline 47 to 61 & $\cdots$ & 0.217 & 0.047 & 1.203 & -0.222 & .283 \\
\hline \multicolumn{7}{|l|}{ Nonwhite } \\
\hline 27 to 36 & $\ldots$ & 0.220 & 0.034 & 0.763 & -0.043 & .136 \\
\hline 37 to 46 & $\cdots$ & 0.199 & 0.055 & 0.718 & -0.246 & .137 \\
\hline \multirow[t]{2}{*}{47 to 61} & $\cdots$ & 0.329 & 0.051 & 0.435 & -0.168 & .167 \\
\hline & \multicolumn{6}{|c|}{ Partial Regression Coefficients, Standard Form } \\
\hline Total & & & & & & \\
\hline 27 to 36 & 0.078 & 0.218 & 0.259 & 0.083 & -0.178 & .277 \\
\hline 37 to 46 & 0.164 & 0.215 & 0.252 & 0.071 & -0.185 & .312 \\
\hline 47 to 61 & 0.165 & 0.238 & 0.251 & 0.113 & -0.169 & .325 \\
\hline \multicolumn{7}{|l|}{ White } \\
\hline 27 to 36 & $\ldots$ & 0.215 & 0.267 & 0.073 & -0.198 & .267 \\
\hline 37 to 46 & $\ldots$ & 0.224 & 0.270 & 0.069 & -0.195 & .281 \\
\hline 47 to 61 & $\cdots$ & 0.234 & 0.270 & 0.122 & -0.184 & .283 \\
\hline \multicolumn{7}{|l|}{ Nonwhite } \\
\hline 27 to 36 & $\ldots$ & 0.245 & 0.157 & 0.105 & -0.044 & .136 \\
\hline 37 to 46 & $\cdots$ & 0.185 & 0.167 & 0.083 & -0.191 & .137 \\
\hline 47 to 61 & $\ldots$ & 0.314 & 0.155 & 0.052 & -0.129 & .167 \\
\hline
\end{tabular}

a Occupations scored on Duncan's socioeconomic index, which has a range of 0 to 96 and a standard deviation of about 24 points in the United States male population aged 25-64 in 1962.

whites (comparing the oldest and heads; hence the contribution of this youngest cohorts) while it increased for nonwhites. The white-nonwhite contrast that is apparently most reliable pertains to occupation of family head. As one can see from the raw-score coefficients, this factor has a similar influence on schooling in both groups. However, the variability of occupation levels is less among nonwhite family variable to educational outcome is of lesser relative importance among nonwhites than among whites when the coefficients are expressed in standard form. For this reason primarily, the coefficient of determination (square of the multiple correlation) is consistently smaller for nonwhites than for whites. The background factors here measured 
account for less of the variation in schooling for nonwhites than they do for whites.

To summarize the over-all effect of family background in producing whitenonwhite differences in schooling, Table 3 presents estimates derived from the regression equations. Comparing the oldest and youngest cohorts, there is a decrease from 3.5 to 2.0 in the mean difference, by color, in number of school years completed. Despite some inconsistency between the alternative estimates of background effects, it appears that both components of this difference have likewise diminished, that is, the difference between whites and nonwhites due to the measured background variables has decreased, while the residual difference, attributed to "color" per se in the regression model, has decreased as well. For the oldest cohort, the difference due to "color" was rather unambiguously larger than the difference due to background; this was no longer true for the youngest cohort. The reason we cannot be completely confident of such a conclusion is simply that the background variables do not have the same weights in the two populations; hence a hypothetical calculation in which they are equalized with respect to background cannot yield a unique result. The conclusion just stated would suggest, however, a slight relaxation of "discrimination," if the residual difference due to "color" is taken to measure discrimination.

One further conclusion can be quite firmly stated. Only a small part of the improvement in educational attainment for both whites and nonwhites can be attributed to improvements in background factors. For whites, the increase in educational attainment, from the oldest to the youngest cohort, amounted to 1.8 school years, of which 0.6 year can be explained by the advantage with respect to background variables enjoyed
TABLE 3-Mean Number of Years of School Completed, by Color, for Selected Age Groups, with Alternative Estimates OF THE EFFECT OF BACKGROUND

DeRIVED From Regressions IN

Table 2, For United States Native Males: March 1962

\begin{tabular}{|c|c|c|c|}
\hline \multirow[b]{2}{*}{ ITEM } & \multicolumn{3}{|c|}{ AGE GROUP } \\
\hline & 27 to & $\begin{array}{c}37 \text { to } \\
46\end{array}$ & $\begin{array}{c}47 \text { to } \\
61\end{array}$ \\
\hline $\begin{array}{l}\text { White Mean School } \\
\text { Years }\end{array}$ & 11.9 & 11.2 & 10.1 \\
\hline $\begin{array}{c}\text { Nonwhite Mean School } \\
\text { Years }\end{array}$ & 9.9 & 8.1 & 6.6 \\
\hline Gross Difference & 2.0 & 3.1 & 3.5 \\
\hline $\begin{array}{l}\text { Difference Due to Back- } \\
\text { ground }\end{array}$ & & & \\
\hline Set A & 1.2 & 1.1 & 1.4 \\
\hline Set B & 1.2 & 0.9 & 1.5 \\
\hline Set $\mathrm{C}$ & 0.9 & 1.4 & 1.6 \\
\hline $\begin{array}{l}\text { Residual Difference Due } \\
\text { to "Color"a }\end{array}$ & & & \\
\hline Set $\mathrm{A}$ & 0.8 & 2.0 & 2.1 \\
\hline Set $B$ & 0.8 & 1.2 & 2.0 \\
\hline Set $\mathrm{C}$ & 1.1 & 1.7 & 1.9 \\
\hline
\end{tabular}

a Set $\mathrm{A}$ : Effect of color estimated as coefficient for color in regression for total population.

Set B : Effect of color estimated by using regression for whites with mean background composition of nonwhites.

Set C: Effect of color estimated by using regression for nonwhites with mean background composition of whites.

by the younger men. For nonwhites, the over-all increase was 3.3 years, while an increase of only 0.6 or 0.8 year (depending on the basis of the calculation) can be attributed to improved circumstances of the family of origin. Of the various handicaps or advantages that a family may confer upon its children, the most important as a determinant of educational attainment is simply year of birth! The youngest cohort of nonwhites almost matches the oldest cohort of whites, so that the combination of background handicaps and those specifically due to "color" is about 
comparable in effect to the passage of two or three decades of time. The residual color effect alone amounts to no more than the amount of change occurring in a decade. (The reader may note that this example shows how multiple-variable studies can provide a breakdown of the Fein gap into its components of general and minorityspecific handicaps.)

\section{Caveat}

All this is relevant to our general goal of freedom from discrimination, however, only on the assumption that educational advance will provide a major part of the solution to the larger problem. There is room for doubt.

For the foreseeable future, closing of the educational gap will mean increasing proportions of Negroes completing high school and attaining some college education short of graduation. But it is at this level of educational attainment that the dissimilarity of occupational levels between whites and Negroes is most pronounced.

In 1960 , the occupation distributions of men 25-34 years old were such that a minimum of 35.4 per cent of the nonwhites would have to be shifted from one major occupation group to another in order for whites and nonwhites to have the same distribution. There was pronounced variation in the amount of net mobility thus required to produce equalization within groupings defined by educational attainment. Siegel ${ }^{28}$ gives

${ }^{28}$ Siegel, op. cit., Table 1. The picture would be even less favorable if we had statistics for Negroes rather than for the misleading composite of all "nonwhites." As Lorimer and Jones point out, "nonwhite" is a "heterogeneous classification used by the census to simplify its tabulations at the cost of providing confused information," Frank Lorimer and Dorothy S. Jones, "The Demographic Characteristics of the Negro Population in the United States," Journal of Negro Education, 22 (Summer 1953), p. 250. the following figures:

\begin{tabular}{lc}
\multicolumn{1}{c}{ Schooling } & $\begin{array}{c}\text { White-NonwhIte } \\
\text { IndEX OP DissimLARITy }\end{array}$ \\
None & 18.6 per cent \\
Elementary, 1-4 & 19.9 \\
Elementary, 5-7 & 26.1 \\
Elementary, 8 & 27.0 \\
High School, 1-3 & 28.2 \\
High School, 4 & 33.4 \\
College, 1-3 & 34.4 \\
College, 4+ & 18.6
\end{tabular}

It is not, therefore, the high school "dropout" who feels the greatest force of occupational discrimination, but the high school graduate or the man who completes some college work short of graduation. To be sure, the college graduate may have to render his professional or technical services in a segregated setting; but he is not prevented to the same degree as the college "dropout" or high school graduate from achieving the occupational level for which his training purportedly prepared him. At the other end of the scale, poorly educated Negroes do not suffer as much relative deprivation as those who attain the minimum standard of elementary schooling.

Some years ago, I had occasion to comment on this circumstance:

It is at the boundary between high school and college educational attainment that the occupational inequality is the greatest. One wonders if we do not have here a good part of the explanation for the recent rise in effective agitation by Negroes for equal rights and opportunities. With goodly numbers of Negroes in the younger cohorts attaining sufficient education to understand their personal situation in social terms, and with the personal situation being one of a rather hard "ceiling" on both educational attainment and occupational mobility, it is hardly surprising that organized and intelligent forms of protest are increasingly in evidence. The coming upsurge in numbers of young adults-those who, among other things, are reaching the age that qualifies them to vote-applies to 
the Negro as well as the white. As compared with, say, the 1930's, when the proportion of adults in the youngest adult age groups was equally high, the cohorts reaching these ages in the 1960's will include much larger proportions who have finished high school and who live in urban areas affording intense personal contacts as well as access to a wide range of mass media of communication. One can only hope that the unrest so easily generated in such a population can lead to constructive organization rather than being dissipated only by costly and unproductive forms of rebellion. ${ }^{28}$

${ }^{29}$ Otis Dudley Duncan, "Population Trends, Mobility and Social Change," presented to the Seminar on Dimensions of American Society, sponsored by the American Association of Colleges for Teacher Education, Committee on Studies, 4-8 October 1961 (ms., p. 58).
Leaving aside the observation that conjectures no more than five years old begin to betray their age, there continues to be validity in the point that educational progress may only mean "that Negroes are just beginning to be exposed to a whole new area of segregation." 30 The inference is weak, to be sure, for the very reason I have been stressing-lack of trend data on interrelationships among components of the socioeconomic life cycle. The development of adequate models and information systems to reveal these interrelationships is prerequisite to specification of the "targets" toward which we would bend the trends.

30 Siegel, op. cit., p. 46. Cf. Hare, op. cit., p. 172 . 